\title{
APROXIMACIÓN A LOS PROBLEMAS FUNDAMENTALES DE LA JUSTICIA TRANSICIONAL. ESPECIAL ÉNFASIS EN LAS SANCIONES IMPONIBLES EN EL MARCO DE LA JURISDICCIÓN ESPECIAL PARA LA PAZ*
}

Luisa Fernanda Caldas Botero ${ }^{* *}$

Resumen: En este documento se exponen diferentes problemas jurídicos que se derivan del acuerdo de justicia al cual llegaron el Gobierno Nacional y los integrantes de las FARC-EP. Así mismo, se analiza con detalle lo relacionado con la imposición de sanciones en la justicia transicional, la teoría de la pena y su aplicación al acuerdo de paz antes referido, a efectos de establecer si lo acordado resulta conforme a la Constitución Política colombiana y a instrumentos internacionales.

Palabras clave: Acuerdos de paz; Jurisdicción especial para la paz; Posconflicto; Justicia transicional; Teorías de la pena.

Ponencia presentada el 4 de abril de 2016 en el Ix Congreso Boyacence de Derecho Procesal. Fecha de recepeción: 20 de abril de 2016. Fecha de modificación: 5 de mayo de 2016. Fecha de aceptación: 24 de junio de 2016. Para citar el artículo: Luisa Fernanda Caldas Botero. "Aproximación a los problemas fundamentales de la justicia transicional. Especial énfasis en las sanciones imponibles en el marco de la jurisdicción especial para la paz”, en Revista Derecho Penal y Criminología, Vol. 38, n. ${ }^{\circ}$ 102, enero-junio de 2016. Bogotá: Universidad Externado de Colombia, pp. 105-120. DOI: http://dx.doi.org/10.18601/01210483.v37n102.06

** Abogada y especialista en ciencias penales y criminológicas de la Universidad Externado de Colombia. Especialista en derecho penal económico y criminalidad organizada de la Universidad de Castilla - La Mancha. Docente de la Universidad Externado de Colombia. Bogotá D.C., Colombia. Correo-e: 1fcalditas@hotmail.com. 


\title{
BRIEF APPROACH TO FUNDAMENTAL ISSUES REGARDING TRANSITIONAL JUSTICE. FOCUS ON CERTAIN PARTICULARITIES OF TAXABLE SANCTIONS WITHIN THE SPECIAL JURISDICTION FOR PEACE
}

\begin{abstract}
This document exposes different trains of thought regarding legal issues as a result of the peace agreement reached by the National Government and FARC-EP (Revolutionary Armed Forces of Colombia-People's Army). The paper shows a detailed analysis in regards of the punishments applied in transitional justice, the differente theories regarding punishment and their application to the agreement reached by both parties, seeking to establish if the agreed is congruent with international agreements and the Constitution. Key words: Peace agreements; Special Jurisdiction for Peace; Transitional Justice; Post-conflict; Theories of Punishment.
\end{abstract}

\section{INTRODUCCIÓN}

Los esfuerzos que en la actualidad se están realizando en Colombia para superar el prolongado conflicto armado y, de esta manera, consolidar una paz estable y duradera, tienen como factor determinante la configuración de un proceso de justicia transicional compuesto por mecanismos de carácter judicial y extrajudicial, cuya principal finalidad es garantizar una verdadera superación del estado de violencia.

Para tal efecto, el Gobierno Nacional y los representantes del grupo armado ilegal FARC-EP suscribieron, el 26 de agosto de 2012, el Acuerdo General para la terminación del conflicto y la construcción de una paz estable y duradera, en el cual se incluyeron diversos aspectos que serían objeto de discusión en el marco del proceso de paz, entre ellos lo relacionado con los derechos de las víctimas (punto n. ${ }^{\circ} 5$ del acuerdo).

En desarrollo de lo anterior, el 15 de diciembre de 2015 se publicó el borrador conjunto en el que se plasmaron las conclusiones a las que llegaron el Gobierno Nacional y las FARC-EP frente al punto de las víctimas y que se denominó "Sistema Integral de Verdad, Justicia, Reparación y No Repetición, incluyendo la Jurisdicción Especial para la Paz; y compromiso sobre Derechos Humanos". En el mencionado documento está todo lo relacionado con los mecanismos judiciales y extrajudiciales que integran el componente de justicia relativo al proceso de paz, es decir, lo referente a la justicia transicional (en sentido estricto, debido a que en sentido amplio podrían incluirse, entre otros, los mecanismos de equidad y participación política desarrollados en otros documentos producto de los acuerdos de La Habana).

Revisado el acuerdo sobre el que versa este artículo, se destaca como positivo que las partes lograron puntos de encuentro en temas que revisten gran importancia dentro de un proceso de paz, tales como: i) los mecanismos para garantizar los derechos de 
las víctimas a la verdad, la justicia, la reparación y la no repetición; ii) los parámetros para determinar la procedencia de amnistías e indultos; iii) los beneficios aplicables a quienes contribuyan a construir una paz estable y duradera y las condiciones que deben cumplir para hacerse acreedores de estos; iv) los organismos encargados de aplicar la justicia transicional y los procedimientos a cargo de estos; entre otros. Si bien los objetivos trazados en el documento al que se viene haciendo referencia se pretenden alcanzar a través de mecanismos judiciales y extrajudiciales, en el marco de este escrito solo se hará referencia a la jurisdicción especial para la paz y a los problemas jurídicos que de ella se derivan.

Incluir en un acuerdo todas las variables que puedan presentarse en un proceso de justicia transicional resulta imposible; siempre existirán aspectos no contemplados que podrían generar problemas importantes en la práctica, por lo que de ninguna manera se pretende aquí realizar una crítica a la magnífica labor desarrollada por todos aquellos que han tenido participación en la negociación respectiva (directa o indirectamente). El propósito es constructivo, en la medida que lo pretendido es la identificación de situaciones que podrían suscitar problemas jurídicos al momento de la aplicación de la justicia transicional y, en consecuencia, en lo posible, proponer soluciones que resulten compatibles con el ordenamiento jurídico nacional e internacional.

\section{ALGUNOS PROBLEMAS JURÍDICOS DERIVADOS DE LA JURISDICCIÓN ESPECIAL DE PAZ}

Revisado el acuerdo, es posible identificar por lo menos ocho temas en los que podrían presentarse problemas jurídicos trascedentes, ya sea porque no fueron contemplados en la negociación o porque sí se previeron pero de forma incompleta. A continuación se enunciará cada uno de ellos:

1. Relaciones entre la jurisdicción especial para la paz y las demás jurisdicciones establecidas en la Constitución Nacional: tratándose de otra jurisdicción que operará en el ordenamiento jurídico interno, se advierte que pueden presentarse diversos inconvenientes en lo relacionado, entre otras cosas, con:

i) La aplicación de acciones constitucionales que protegen derechos fundamentales como la tutela y el habeas corpus. En otros términos, la interrogante que se presenta es si una persona sometida a la jurisdicción especial de paz puede hacer uso de tales mecanismos de rango constitucional para proteger los derechos fundamentales que eventualmente le sean vulnerados.

ii) La articulación de los procesos que se adelantan al amparo de la Ley 975 de 2005 , ley de justicia y paz, en contra de excombatientes de grupos armados ilegales, principalmente autodefensas, aunque no de forma exclusiva, quienes, de conformidad con el acuerdo de justicia transicional, también pueden ser sujetos de la jurisdicción 
especial de paz. Lo anterior, con mayor razón si se tiene en cuenta que, como se verá adelante, el acuerdo del año 2015 resulta más benéfico en relación con el otorgamiento de amnistías e indultos y de penas alternativas.

iii) Las autoridades competentes y el procedimiento aplicable en la resolución de conflictos entre la jurisdicción especial para la paz y las demás jurisdicciones, eventualidad sobre la cual ni siquiera se hizo referencia en el acuerdo.

2. Conflicto de competencias entre la jurisdicción especial de paz y las diversas ramas del poder público: aun cuando el acuerdo no lo contemple, podría afirmarse que, en principio, la jurisdicción especial de paz haría parte de la rama judicial. No obstante, también podría aseverarse que se trata de un organismo sui generis que no puede adscribirse a ninguna rama del poder público.

En cualquier hipótesis, lo cierto es que a los órganos que componen la jurisdicción especial para la paz se les asignaron funciones que pueden entrar en conflicto con las atribuciones que constitucionalmente tienen diferidas la rama legislativa y ejecutiva. Por ejemplo, en relación con la concesión de indultos y amnistías que en la Constitución se atribuyen al Congreso de la República y en los acuerdos a un órgano de la jurisdicción para la paz, a saber, la sala de amnistías e indultos.

3. Contradicciones entre el marco jurídico para la paz y los acuerdos: si bien las disposiciones contenidas en el acto legislativo 01 de 2012, conocido como marco jurídico para la paz, son amplias y, en su mayoría, no tienen la calidad de taxativas, en algunos temas como la determinación de los criterios de selección y priorización de casos y máximos responsables, es enfática en que estos se desarrollarán mediante una ley expedida por el Congreso de la República -salvo los criterios de priorización que se le asignan a la Fiscalía General de la Nación-.

Sin embargo, el acuerdo que se viene analizando autoriza a órganos que integran la jurisdicción de paz para adoptar tales criterios. Esta problemática conduce a un asunto aún más complejo, consistente en determinar cuáles son las fuentes que trazan los límites que deben respetar los acuerdos: si es la Constitución de manera integral; si son solamente los actos legislativos creados de forma especial para el desarrollo del proceso de paz; si únicamente se aplican disposiciones de derecho internacional, entre otros. En síntesis, se trata de un asunto que debe ser resuelto antes de la firma final de los acuerdos, debido a que su indeterminación podría poner en riesgo la consolidación del proceso de justicia transicional.

4. Partes e intervinientes en el proceso y sus roles: no se determinó de forma clara quienes serían las partes e intervinientes en los procesos que se adelantarán por la jurisdicción especial de paz, ni tampoco de sus roles en el desarrollo de estos. Aquí se destaca la ausencia de parámetros claros en referencia a la víctima, eje central del proceso de justicia transicional. Por ejemplo, no se definió cuáles son las prerrogati- 
vas que tiene dentro del proceso; cómo y en qué calidad puede participar dentro de este; si su facultad de solicitar revisión de casos ya fallados por la justicia ordinaria comprende las sentencias absolutorias frente a hechos ocurridos en el marco del conflicto; etc.

5. Tratamiento de los agentes del Estado: es un tema que se reguló de manera tangencial, quedando por definir múltiples aspectos que resultan esenciales para la justicia transicional, en la medida que es uno de los más problemáticos, en especial, porque suscita gran atención para los organismos internacionales, entre otras razones, por la imperiosa necesidad de que no haya impunidad y porque de su correcta regulación depende el éxito o fracaso del proceso de paz. Vale la pena destacar que, precisamente sobre el tratamiento de los agentes del Estado, Human Rights Watch presentó un informe el 29 de marzo de 2016, en el cual manifestó su preocupación por el tratamiento que se pueda dar a los casos de "falsos positivos" bajo las disposiciones de la jurisdicción especial para la paz.

6. Ausencia de mecanismos que garanticen el cumplimiento de las obligaciones impuestas por la justicia transicional: específicamente, se hace referencia a la no consagración de mecanismos que permitan garantizar que las personas que accedieron a beneficios propios de la justicia transicional como amnistías, indultos, rebajas de penas, penas alternativas, etc., luego de haberlos recibido cumplan con las obligaciones que les fueron impuestas.

En otras palabras, dicho tratamiento preferencial es condicionado, pero no se contempló ninguna forma para hacer efectivos los compromisos o, por lo menos, para eliminar los beneficios cuando ha habido incumplimiento por parte de su destinatario. Por ejemplo, en el evento de otorgamiento de amnistías que, como lo contempla el acuerdo, no eximen al beneficiado de la obligación de aportar verdad, reparar y conceder garantías de no repetición, no se consagró ningún mecanismo para retrotraer el beneficio a quien incumple.

7. Imposición y revisión de sanciones por parte de la jurisdicción especial de paz: en relación con este punto, el cual se desarrollará en el siguiente acápite, es indispensable mencionar que son tres los temas que generan problemas en la práctica: el primero, la revisión y acumulación de sanciones de carácter administrativo, fiscal, disciplinario y penal en la jurisdicción especial de paz, debido a que los criterios de extinción, de revisión y de anulación de las decisiones tomadas por otras jurisdicciones no fueron establecidos y, menos aún, las reglas aplicables en caso de una posible acumulación jurídica de sanciones que, como se sabe, tienen naturaleza jurídica diferente, lo cual hace más complejo el asunto. El segundo, la determinación de sanciones para los agentes del estado, asunto que quedó en completa indefinición y que, como se afirmó, constituye un tema central para el éxito del proceso de paz. El tercero son el contenido y la aplicación de las denominadas sanciones propias, sanciones alternativas y sanciones ordinarias para los casos seleccionados. 
8. Interpretación y complementación de los acuerdos: conforme lo que se acaba de exponer, se puede sostener que, en muchas ocasiones, los acuerdos deben ser complementados e interpretados por terceros ajenos a las partes que los suscribieron. En consecuencia, debe establecerse quiénes son las autoridades encargadas de realizar la mencionada complementación y, así mismo, cuáles son los límites aplicables. La ausencia de esta determinación conllevaría a gravísimos conflictos entre las partes que suscribieron los acuerdos, debido a que al momento de advertir omisiones que hagan inaplicables algunas disposiciones del acuerdo y dar soluciones para hacer operativas las instituciones, se podría considerar que se trata de una extralimitación, lo que generaría un alto riesgo para la consolidación y estabilidad de los acuerdos de paz.

Desarrollar todos los ítems mencionados en una conferencia es imposible debido a la complejidad y la multiplicidad de temas que cada problemática involucra. Por tal razón, solo se seleccionará uno de ellos, a saber, el relativo a las sanciones contempladas en la jurisdicción especial de paz, conforme se expondrá en el siguiente acápite.

\section{PROBLEMAS ESPECÍFICOS DERIVADOS DE LA IMPOSICIÓN DE SANCIONES EN LA JURISDICCIÓN ESPECIAL PARA LA PAZ}

Se ha seleccionado este tema para su desarrollo debido al importante contenido y trascendencia que ha tenido la teoría de la pena en el derecho y que, como se verá a continuación, mantiene su vigencia a efectos de la justicia transicional ${ }^{1}$ porque no debe olvidarse que se sigue tratando de un juicio de carácter penal en el cual se analiza la responsabilidad de algunas personas por delitos de gran impacto para los derechos humanos -crímenes de lesa humanidad, genocidio, crímenes de guerra, etc.y que aun con las variaciones y particularidades propias de la justicia de transición, se aplican penas y no simples sanciones desprovistas de reproche.

1. En concordancia con lo anterior, la primera pregunta que se debe hacer es: ¿Qué fines se persiguen con la imposición de penas en el marco de un proceso de justicia transicional? Para responder a este interrogante, es indispensable poner de presente que cada proceso de justicia transicional es diferente y sus instituciones están delimitadas por las particularidades del conflicto que se pretende resolver, razón por la cual, en relación con los procesos de justicia transicional, es imposible aseverar la existencia de parámetros idénticos para todos los casos, tal como lo ha reconocido, entre otros organismos, el Consejo de Seguridad de las Naciones Unidas ${ }^{2}$.

No obstante, tanto en la doctrina como en la jurisprudencia y los instrumentos internacionales, se han establecido algunos principios mínimos que deben respetarse en

1 En igual sentido, Uprimny YePES; SÁNChez DuQue y SÁNCHEZ (2013).

2 Informe del Secretario General de las Naciones Unidas fechado 3 de agosto de 2004, S/2004/616. 
cualquier proceso de justicia transicional, entre ellos: i) el deber de los Estados de investigar y sancionar las graves violaciones a los derechos humanos y los crímenes internacionales; ii) garantizar los derechos de las víctimas a la verdad, la justicia, la reparación y no repetición, y iii) la preservación de la paz, la construcción de la democracia y del estado de derecho ${ }^{3}$.

De los principios mínimos de la justicia transicional es posible obtener una orientación para responder a la pregunta de ¿qué se pretende con la imposición de la pena en el marco de la misma? Podría aseverarse que se presentaría una combinación de factores derivados de las tradicionales teorías de la pena ${ }^{4}$ y de los especiales fines que persigue la justicia transicional, a saber:

i) La prevención general negativa enfocada a que la sociedad comprenda que este tipo de comportamientos son reprochados por el Estado y que en procesos de carácter especial, como la justicia transicional, en los cuales la justicia cede ante la consolidación de la paz, se hacen efectivas las penas.

ii) La prevención general positiva, en la medida que se reafirma la confianza en las instituciones y las normas que contienen las disposiciones que prohíben los comportamientos que constituyen las más graves violaciones a los derechos humanos.

iii) La prevención especial porque se brinda al desmovilizado la posibilidad de reincorporarse a la vida civil, a través de diversos programas que se establecen con la finalidad de facilitar este procedimiento y lograr la reconciliación entre los actores del conflicto y la sociedad. De igual manera, se trata de evitar que la persona desmovilizada continúe cometiendo comportamientos delictivos.

iv) La retribución porque aunque no se diga de forma explícita, en la aplicación de cualquier pena existe un ingrediente de retribución así este se entienda solo como un límite para la graduación de la pena. No obstante, aquí debe aclararse que en la justicia transicional normalmente la graduación de la sanción no tiene una correspondencia directa con la gravedad del comportamiento, debido a que este ejercicio se afecta por la ponderación de los diversos intereses involucrados en un proceso de paz, lo que tiene como consecuencia que con el propósito de alcanzar intereses como la paz y la consolidación del estado de derecho, se deban hacer concesiones no permitidas en el derecho penal ordinario.

Adicional a las finalidades tradicionales de la pena debe reconocerse que en el derecho existe una tendencia moderna consistente en adjudicar una finalidad restaurativa ${ }^{5}$ a

3 Cfr., entre otros, Ambos (2014), Malarino y Elsner (2009), Teitel (2003).

4 Cfr. UPRIMnY (Op. cit., pp. 62 y 109 y ss.).

5 Cfr. Roxin (1999, pp. 108-110); de manera más reciente, HöRnLE (2015, pp. 33 y ss.). 
la pena, la cual si bien no ha sido plenamente aceptada y desarrollada por el derecho penal ordinario, sí tiene importantes implicaciones en la justicia transicional, en la medida en que, precisamente, uno de sus principales objetivos es resarcir a las víctimas de las graves violaciones de los derechos humanos.

También debe destacarse que instrumentos internacionales suscritos y ratificados por Colombia, que versan sobre materias directamente relacionadas con la justicia transicional, como el Estatuto de Roma de la Corte Penal Internacional, imprimen sus propias finalidades a las penas. En este caso específico, se contempla el objetivo de evitar la impunidad y prevenir nuevos crímenes (preámbulo del estatuto). En palabras del Fiscal Adjunto de la Corte Penal Internacional, James Stewart, el objetivo de la pena en el mencionado estatuto es la condena pública de la conducta criminal, el reconocimiento del sufrimiento de las víctimas y la disuasión de conductas criminales ulteriores (STEWART, 2015).

En el caso concreto de los acuerdos de paz de La Habana, se estipuló que el fin de la pena es la satisfacción de los derechos de las víctimas, la consolidación de la paz y la función reparadora y restaurativa. En consecuencia, puede aseverarse que para nuestro proceso de paz lo que pretendieron las partes fue darle a la pena una finalidad en la que tienen prevalencia los derechos de las víctimas y la paz.

Aun cuando en el derecho penal ordinario se ha criticado la utilización de las teorías de la unión, esto es, tesis que incluyen como finalidades de la pena la reunión de todas las anteriores ${ }^{6}$, en la práctica se hace imposible aseverar que la pena pueda fundamentarse en solo una de las teorías existentes en la doctrina. Por su parte, la legislación y jurisprudencia de nuestro país ${ }^{7}$ han aceptado como válido que se persigan diferentes finalidades en la imposición de la pena, situación que, como se puede concluir de lo antes expuesto, no varía para la justicia transicional, en la que se combinan fines preventivos especiales, preventivos generales, retribución y reparación.

No obstante, debe tenerse en cuenta que cualquier interpretación que se haga en este tema debe tener como finalidad última garantizar los derechos de las víctimas y permitir el logro de la paz, por lo que seguramente será indispensable hacer uso de instrumentos como el test de proporcionalidad para establecer si la renuncia a unas penas drásticas, proporcionales a la gravedad de los delitos objeto de la justicia transicional, se justifica y es necesaria para alcanzar tales objetivos.

2. Establecido lo anterior, es preciso determinar si las penas contenidas en el acuerdo de justicia analizado sirven o no para garantizar los fines antes propuestos. Para

6 Cfr., entre otros, LESCH (2000).

7 Artículo 4 del Código Penal colombiano. Ver, entre otras, las Sentencias C-430 de 1996 y C-261 de 1996. 
responder a este interrogante, es imprescindible exponer las tres clases de penas aplicables por la jurisdicción especial para la paz, a saber:

i) Sanciones propias: aplicables a quienes reconozcan verdad y responsabilidad ante la Sala de Reconocimiento de Verdad, respecto de graves infracciones. Tienen un mínimo 5 años y un máximo de 8 años de restricción efectiva de libertades y derechos, tales como los de residencia y de movimiento. Por restricción efectiva se entiende la existencia de mecanismos idóneos de monitoreo y supervisión que garanticen su cumplimiento y permitan certificarlo. En ningún caso pueden consistir en cárcel o prisión, ni adopción de medidas de seguridad o equivalentes. Los comparecientes podrán presentar un proyecto individual o colectivo que contemple actividades restaurativas.

ii) Sanciones alternativas: se impondrán a quienes reconozcan, antes de sentencia, verdad y responsabilidad por graves infracciones, ante la sección de enjuiciamiento del Tribunal para la Paz. Se afirma, en el acuerdo, que tiene una función eminentemente retributiva y consiste en la imposición de una pena privativa de libertad de 5 a 8 años. Para su determinación, se tendrán en cuenta las normas del código penal y luego se impondrá una pena alternativa de 5 a 8 años, siempre y cuando se presente un compromiso de resocialización y para la graduación de la sanción se tendrán en cuenta las razones que tuvo el compareciente para no reconocer la verdad con anterioridad. Se excluye la aplicación de cualquier subrogado o beneficio adicional a la pena alternativa.

iii) Sanciones ordinarias: aplicables a los casos en los que no hay reconocimiento de verdad y responsabilidad, por lo que, según lo afirmado en el acuerdo, cumplirá las funciones previstas en el código penal y se regirá por las reglas de dicho estatuto, salvo lo relacionado con la duración de la pena, para la que se establece una excepción, debido a que la privación efectiva de la libertad mínima es de 15 años y la máxima de 20 años. Aplican subrogados penales o beneficios adicionales siempre que el destinatario se comprometa a contribuir con su resocialización.

Como se puede observar, se trata de tres escenarios punitivos en los que se otorga un tratamiento especial en razón a los factores propios de la justicia transicional, a saber:

En el caso de las denominadas sanciones propias, que comportan un tratamiento absolutamente benigno para quienes acepten en primer término responsabilidad por graves infracciones a derechos humanos y reconozcan la verdad, se concede un beneficio que se representa más que en los términos mínimos y máximos de la pena (5 a 8 años), en la exclusión de la privación efectiva de la libertad, caso en el cual es indispensable determinar si en el marco de la justicia transicional resulta admisible dicho tratamiento para máximos responsables de delitos que comportan graves violaciones de los derechos humanos. 
Frente a las sanciones alternativas, puede aseverarse que también se contemplan penas benignas, pero en este caso más por el término de duración de 5 a 8 años que por la restricción de derechos, debido a que en este evento se hace efectiva la privación de la libertad. Aquí lo que modifica el tratamiento, esto es, lo que hace que la sanción sea más severa en comparación con el escenario punitivo anterior es que la persona, si bien acepta responsabilidad y reconoce verdad, lo hace en un estado más avanzado del proceso de justicia transicional.

Finalmente, en lo que respecta a las sanciones ordinarias consistentes en la privación efectiva de la libertad por un período de 15 a 20 años, las cuales resultan aplicables a quienes no aceptan responsabilidad ni aportan verdad y son encontrados culpables en juicio, debe afirmarse que, en comparación con las penas aplicables en el derecho penal ordinario, donde por ejemplo el genocidio se sanciona con prisión de 40 a 50 años, también se concede un importante beneficio en la justicia transicional representado en el mínimo y máximo de la sanción, el que, aun cuando no lo afirma el acuerdo, se podría entender que está fundamentado en que la persona se desmovilizó y dejó las armas. En otros supuestos, sería insostenible esta significativa rebaja punitiva.

La pregunta que debe resolverse es si tales penas resultan adecuadas a las finalidades de la justicia transicional; en otras palabras, si estos tratamientos preferenciales se ajustan a la Constitución y a los instrumentos internacionales. En principio, podría afirmarse que la respuesta a este interrogante es positiva si se tiene en cuenta que, por lo menos de forma abstracta, la Corte Constitucional colombiana, al analizar la exequibilidad del marco jurídico para la paz, consideró que luego de hacer una ponderación entre los derechos a la justicia y a la paz podrían permitirse penas alternativas y penas no privativas de la libertad. Aseveró textualmente la Corporación en la Sentencia C-579 de 2013:

... las penas alternativas y los mecanismos especiales para el cumplimiento de la pena como mecanismos ordinarios o de justicia transicional son plenamente aceptados por la comunidad internacional y además han sido estudiados precisamente por esta Corporación, llegando a la conclusión de que no vulneran ninguna norma constitucional, por lo cual menos aún pueden considerarse como una sustitución de la Constitución. Estos mecanismos se fundan en la necesidad de hacer compatibles la justicia con la reconciliación y la no repetición de las conductas a través de sistemas que estén enfocados en la finalidad preventiva de la pena más allá de la retribución...

No obstante lo anterior, es indispensable resaltar que la constitucionalidad y aceptación del mencionado tratamiento especial para crímenes graves encuentra fundamento principal en la contraprestación que el beneficiado está dando para lograr la paz y la reconciliación, es decir, en los aportes realizados antes de la imposición de la pena, entre ellos la desmovilización, la dejación de armas, la entrega de secuestrados, la aceptación de responsabilidad, el reconocimiento de verdad, etc., pero también en 
los compromisos que suscribe para el futuro, como la reparación, la resocialización y las garantías de no repetición. Es decir, se trata de un beneficio que se otorga por comportamientos positivos del procesado, unos anteriores y otros posteriores a la imposición de la pena.

En relación con las condiciones previas al otorgamiento del beneficio, al tratarse de hechos superados al momento de la imposición de la pena, no existe reparo de ninguna naturaleza. Son los compromisos posteriores a la pena los que presentan graves problemas de compatibilidad con los instrumentos nacionales e internacionales, en la medida en que su incumplimiento no fue previsto en el acuerdo y, en consecuencia, no tienen ninguna sanción. En otras palabras, en los términos actuales del acuerdo, una persona que es beneficiada con una pena de 5 a 8 años de restricción de derechos diferentes a la libertad, que incumpla su compromiso de reparación o que vuelva a delinquir, supóngase con la creación de nuevos grupos armados al margen de la ley -como ocurrió con algunos paramilitares- seguirá disfrutando de dichos beneficios.

Precisamente, la misma jurisprudencia de la Corte Constitucional permite aseverar que es indispensable que se incluya un mecanismo que permita revocar los beneficios y aplicar las penas plenas para los delitos tal como las consagra el código penal o, por lo menos, convertir las penas restrictivas de otros derechos en penas privativas de la libertad para quienes incumplan con las obligaciones que les permitieron gozar del tratamiento más benigno contemplado en la justicia transicional.

Frente a este asunto, la Corte Constitucional, desde el momento en que estudió la constitucionalidad de la ley de justicia y paz, aseveró que para que este tratamiento especial fuera compatible con la Constitución, debía tenerse en cuenta que se trataba de una pena condicionada a la satisfacción de unos compromisos y que al momento de presentarse incumplimiento se rompía el equilibrio que permitía considerar constitucionales dichas penas alternativas.

Expuso textualmente la Corte en la Sentencia C-370 de 2006:

En esencia, la alternatividad penal es un beneficio consistente en suspender la ejecución de la pena ordinaria aplicable en virtud de las reglas generales del Código Penal, para que en lugar de cumplir esta pena ordinaria, el condenado cumpla una pena alternativa menor, de un mínimo de 5 años y de un máximo de 8 años. En la sentencia condenatoria, primero, se fija la pena ordinaria (la principal y las accesorias), y, segundo, se reemplaza dicha pena, cuya ejecución es suspendida por ministerio de la ley, por la pena alternativa de 5 a 8 años, entre otras determinaciones que han de tomarse en la sentencia. En el concepto de alternatividad penal adoptado en la ley 975 de 2005 la pena ordinaria no desaparece, sino que es fijada en la sentencia. Lo que sucede es que el condenado que reúna los requisitos establecidos en dicha ley se beneficia con una pena alternativa inferior que también ha de 
ser fijada en la sentencia. Es esta pena alternativa la que efectivamente debe cumplir el condenado.

\section{$(\ldots)$}

Aparentemente, una pena que oscile entre cinco y ocho años de prisión podría resultar desproporcionadamente baja cuando se trata de grave criminalidad. Entonces es preciso determinar cuál es el sentido y el alcance de la ley en materia de imposición punitiva para desentrañar la naturaleza de esa pena y si la misma vulnera el valor justicia o los derechos de las víctimas.

\section{$(\ldots)$}

(i) Es un beneficio punitivo que conlleva suspensión condicional de la ejecución de la pena determinada en la respectiva sentencia, el cual responde a características y propósitos específicos.

(ii) Es judicial y sustitutiva de la pena ordinaria: la autoridad judicial competente impondrá en la sentencia la pena principal y las accesorias que correspondan de ordinario al delito conforme a los criterios establecidos en la ley penal. Esta comprensión se deriva explícita y sistemáticamente de los artículos 3, 19, 20, 24 y 29.

(iii) Es alternativa: la pena que de ordinario le correspondería cumplir al condenado es reemplazada por una pena inferior de tal forma que el condenado debe pagar la pena alternativa, no la pena ordinaria inicialmente impuesta.

(iv) Es condicionada: su imposición está condicionada a que concurran los presupuestos específicos previstos en la presente ley. Verificado su cumplimiento, el Tribunal impondrá lo que la ley denomina pena alternativa.

\section{$(\ldots)$}

(vi) Su mantenimiento depende de la libertad a prueba: una vez cumplida efectivamente la pena alternativa, así como las condiciones impuestas en la sentencia según la ley (artículo 24), se concederá la libertad a prueba por un término igual a la mitad de la pena alternativa impuesta, período en el cual el sentenciado debe cumplir determinados compromisos: no reincidir en ciertas actividades delictivas, presentaciones periódicas e información de cambio de residencia (artículo 29).

... La imposición de una pena alternativa no anula, invalida o extingue la pena originaria. La extinción solo se produce una vez cumplida, en su totalidad, la 
pena alternativa impuesta, el período de prueba y cumplidas las obligaciones derivadas de todos los requisitos impuestos para el otorgamiento del beneficio.

\begin{abstract}
6.2.1.4.9. Esta configuración de la denominada pena alternativa, como medida encaminada al logro de la paz resulta acorde con la Constitución en cuanto, tal como se deriva de los artículos 3 y 24, no entraña una desproporcionada afectación del valor justicia, el cual aparece preservado por la imposición de una pena originaria (principal y accesoria), dentro de los límites establecidos en el Código Penal, proporcional al delito por el que se ha condenado, y que debe ser cumplida si el desmovilizado sentenciado incumple los compromisos bajo los cuales se le otorgó el beneficio de la suspensión de la condena. Estos aspectos de la ponderación han sido analizados en los apartados 5, 6.2.1.7. y 6.2.2. de la presente providencia (destacado fuera de texto).
\end{abstract}

Si bien se trata de un estudio que se efectuó en el marco de la justicia transicional derivada de la Ley 975 de 2005, las consideraciones son perfectamente aplicables al caso concreto en la medida en que no existe ningún elemento que permita aseverar que a los beneficiados con los acuerdos de La Habana se les pueda permitir la violación de sus compromisos sin ninguna consecuencia y, con mayor razón, si esta transgresión comporta una afectación directa a los derechos de las victimas tales como la reparación y las garantías de no repetición. En los dos supuestos, la persona incumple las exigencias que le hacen merecedora de un tratamiento especial y, en consecuencia, desaparecen las condiciones que permiten justificar el tratamiento diferencial.

Tan cierto resulta lo anterior que en la Sentencia C-579 de 2013, referida al marco jurídico para la paz, expuso la Corte que la renuncia a la acción penal es condicionada y, en ese sentido, el incumplimiento por parte del beneficiado permite activar de nuevo la acción penal. Afirmó la Corporación:

... expresión "renuncia condicionada" tiene una consecuencia muy importante y es que de no cumplirse los requisitos señalados en la ley estatutaria, los cuales como mínimo deben ser los contemplados en el inciso quinto del artículo 1 del Marco Jurídico para la Paz (la dejación de las armas, el reconocimiento de responsabilidad, la contribución al esclarecimiento de la verdad y a la reparación integral de las víctimas, la liberación de los secuestrados, y la desvinculación de los menores de edad reclutados ilícitamente que se encuentren en poder de los grupos armados al margen de la ley) se podrá revocar inmediatamente la renuncia a la persecución y el Estado recobrará toda su potestad para investigar, juzgar y sancionar a los responsables por todos los delitos cometidos en el marco de la justicia ordinaria (destacado fuera de texto). 
Si bien esta consideración se hizo en referencia a la renuncia a la acción penal, con mayor razón opera para casos en los cuales no hay renuncia, pero por la gravedad de los delitos y la calidad de máximos responsables de sus autores, se trata de la aplicación de beneficios punitivos bastante significativos con el mismo fundamento, esto es, los compromisos adquiridos por el destinatario de la justicia transicional.

Finalmente, debe tenerse en cuenta que para organismos internacionales como la Corte Penal Internacional y la Corte Interamericana de Derechos Humanos constituye un requisito indispensable para la evaluación del cumplimiento de los derechos de las víctimas, entre ellos, la justicia y la no impunidad, además de la imposición de la sanción, el cumplimiento efectivo de la misma.

En efecto, aseveró la Corte IDH en Sentencia de 25 de octubre de 2012, caso Masacre de El Mozote y lugares aledaños vs. El Salvador:

“244. Ahora bien, la obligación de investigar, como elemento fundamental y condicionante para la protección de ciertos derechos afectados, adquiere una particular y determinante intensidad e importancia ante la gravedad de los delitos cometidos y la naturaleza de los derechos lesionados, como en casos de graves violaciones de los derechos humanos, ocurridas como parte de un patrón sistemático o práctica aplicada o tolerada por el Estado o en contextos de ataques masivos y sistemáticos o generalizados hacia algún sector de la población, pues la necesidad imperiosa de prevenir la repetición de tales hechos depende, en buena medida, de que se evite la impunidad y se satisfagan las expectativas de la víctima y la sociedad en su conjunto de acceder al conocimiento de la verdad de lo sucedido. La eliminación de la impunidad, por todos los medios legales disponibles, es un elemento fundamental para la erradicación de las ejecuciones extrajudiciales, la tortura y otras graves violaciones de los derechos humanos".

\section{$(\ldots)$}

"249. ... dicho deber impone la remoción de todo obstáculo de jure y de facto que impida la investigación y juzgamiento de los hechos y, en su caso, la sanción de todos los responsables de las violaciones declaradas así como la búsqueda de la verdad. En efecto si el aparato del Estado actúa de modo que tal violación quede impune y no se reestablece, en cuanto sea posible, a las víctimas en la plenitud de sus derechos, puede afirmarse que ha incumplido el deber de garantizar su libre y pleno ejercicio a las personas sujetas a su jurisdicción" (destacado fuera de texto).

Sobre el mismo tema, es importante citar el informe presentado por la Fiscalía de la Corte Penal Internacional en el año 2012, en el cual aseveró que 
... examinará la cuestión de las sentencias, incluidas las sentencias reducidas y las suspendidas, a la luz de los hechos y las circunstancias de cada caso. En concreto, la Fiscalía determinará si en la aplicación de esas disposiciones se han realizado esfuerzos razonables por establecer la verdad acerca de los crímenes graves... si se ha establecido la responsabilidad penal adecuada de esos crímenes... si, en las circunstancias, cabe decir que la sentencia es consistente con la intención de llevar ante la justicia a la persona en cuestión..." (destacado fuera de texto).

En conclusión, a efectos de garantizar los derechos de las víctimas y de ser consecuentes con los beneficios que se otorguen en el marco de la justicia transicional, pero también, de manera colateral, para evitar futuros problemas de constitucionalidad y de activación de competencia de organismos internacionales, es indispensable que se creen mecanismos que permitan sancionar el incumplimiento de las exigencias que hacen posible la activación de los beneficios de la justicia transicional. La solución no necesariamente debe ser idéntica a la adoptada en el marco de la ley de justicia y paz, sin embargo, debe considerarse el endurecimiento de la sanción para tales casos porque, de otra forma, se pondría en riesgo el objetivo de lograr una paz estable y duradera.

\section{BIBLIOGRAFÍA}

Ambos, Kai; Malarino, Ezequiel y Elsner, Gisela (ed.) (2009). Justicia transicional. Informes de América Latina, Alemania, Italia y España. Uruguay: GeorgAugust - Universität - Göttingen, Konrad Adenauer Stiftung.

Código Penal colombiano.

Corte Constitucional. Sentencias C-370 de 2006, C-579 de 2013, C-430 de 1996 y C-261 de 1996.

LeSCH, Heiko H. (2000). La función de la pena. Bogotá: Universidad Externado de Colombia.

NaCiOnes Unidas (2004). Informe del Secretario General de las Naciones Unidas S/2004/616.

Roxin, Claus (1999). Derecho penal - Parte general. Fundamentos. La estructura de la teoría del delito, 2. ${ }^{a}$ Madrid: Edición Ed. Civitas, pp. 108-110. De manera más reciente: Tatjana Hörnle (2015). Teorías de la penal. Bogotá: Universidad Externado de Colombia, pp. 33 y ss. 
STEWART, JAMES (2015). La Justicia transicional en Colombia y el papel de la Corte Penal Internacional. Conferencia pronunciada por el Fiscal Adjunto de la Corte Penal Internacional, el 13 de mayo de 2015.

Teitel, Ruti G. (2003). Genealogía de la Justicia Transicional. Chile. Disponible en www.cdh.uchile.cl/media/publicaciones/pdf/18/59.pdf.

Uprimny YePes, Rodrigo; SÁnchez DuQue, LuZ María; SÁnchez, Nelson CAmilo (2013). Justicia para la paz. Crímenes atroces, derecho a la justicia y paz negociada. Bogotá: Colección Dejusticia. 